\title{
All for One and One for All! Disparity Between Overall Crew's and Individual Rowers' Pacing Strategies During Rowing
}

\author{
Andrew Renfree, Louise Martin, Ashley Richards, and Alan St Clair Gibson
}

\begin{abstract}
Purpose: This study examined individual contributions to overall pacing strategy during 2- and 5-km rowing trials in a coxless-4 boat. Methods: A crew of 4 male rowers performed maximal-effort on-water trials over 2 and $5 \mathrm{~km}$, and power output during every individual stroke was measured for each crew member. Mean overall boat and individual rower stroke power were calculated for each $25 \%$ epoch ( $25 \%$ of total strokes taken), and power for each individual epoch was calculated as a percentage of mean power maintained over the entire distance. The coefficient of variation was used to determine stroke-tostroke and epoch-to-epoch variability for individual rowers and the overall boat. Results: In both trials, the overall pacing strategy consisted of a high power output in the initial $25 \%$ that decreased in the middle $50 \%$ and increased again in the final $25 \%$. However, individual rower data indicate wide variation in individual power profiles that did not always mimic the overall boat profile. Conclusions: This study demonstrates that overall boat power profiles during 2- and 5-km rowing trials are similar to velocity profiles previously reported for individual ergometry and on-water racing events. However, this overall profile is achieved despite considerable variation in individual rower profiles. Further research is warranted to determine the mechanisms through which individual contributions to overall pacing strategy are regulated and the effectiveness or otherwise of seemingly disparate individual strategies on overall performance.
\end{abstract}

\section{Keywords[AUQ1]:}

The distribution of workload throughout an event is termed pacing, and the appropriate distribution of energetic resources is essential to successful performance. ${ }^{1}$ During 2000-m rowing, a common parabolic race profile has been reported in both on-water ${ }^{2}$ and ergometer ${ }^{3,4}$ events. Race profiles have been determined through calculation of mean boat speed every $500 \mathrm{~m}$ using split times. These data indicate that boat speed is fastest over the opening $500 \mathrm{~m}$, decreases throughout the middle $1000 \mathrm{~m}$, and increases again over the final $500 \mathrm{~m}$.

Almost all previous studies have reported total boat speed when analyzing pacing strategies during rowing. One study investigated the coordination and consistency of rowers in a racing- 8 and demonstrated that individual force-time profiles when the oar is in the water remain preserved throughout a 22-minute training run. ${ }^{5}$ However, that work used a submaximal exercise bout rather than a maximal-effort trial and did not report individual or overall boat power profiles, which relate to the distribution of muscle work rate over the duration of a competitive effort. No published study has reported individual rower or overall boat power profiles during on-water rowing. The aim of this case study was therefore to describe overall and individual rower power profiles of a coxless-4 boat during 2- and 5-km time trials.

The authors are with the Institute of Sport and Exercise Science, University of Worcester, Worcester, UK.

\begin{abstract}
Method
A crew of 4 male rowers $(20.8 \pm 1.5 \mathrm{y}, 79.5 \pm 11.1 \mathrm{~kg})$ who were actively competing at British Rowing Intermediate standard and had at least 3 years experience at varsity level participated in this study, which had institutional ethics committee approval.

After familiarization trials, the crew performed maximal-effort on-water trials over 2 and $5 \mathrm{~km}$ in a Janousek 4 boat (Janousek Racing. Surrey, UK). The oarlocks were removed and replaced with PowerLine gates (Peach PowerLine systems, Peach Innovations Ltd, Cambridge, UK). The PowerLine system was interfaced to a PC equipped with PowerLine V3-3 software, which calculated power output (W) generated during each stroke. Power was calculated based on the integral of force on the handle multiplied by handle speed, both of which were reduced to their components in the $x$ direction. Handle speed was taken as the difference between angle measurements recorded at $50 \mathrm{~Hz}$. The validity and reliability of both force and angle measurements generated have been determined, and the system appears appropriate for measuring biomechanical variables in an elite sculling program. ${ }^{6}$ The system was calibrated before each trial using the PowerLine logger.

For both trials, mean overall boat and individual rower stroke power were calculated for each $25 \%$ epoch ( $25 \%$ of total strokes taken), and power for each individual epoch was calculated as a percentage of mean power maintained over the entire distance. The coefficient of variation $(\mathrm{CV})$ was calculated to determine epoch-to-
\end{abstract}


epoch and stroke-to-stroke variability in power output for each rower and the overall boat.

\section{Results}

Power profiles for both trials indicate that the overall pacing strategy consisted of a high power output in the initial $25 \%$ that decreased in the middle $50 \%$ and increased again in the final $25 \%$ (Figure 1). Although overall power profiles are similar, the magnitude of variation in power output from one epoch to another differed between trials. The CVs of power output between epochs were $7.99 \%$ for the overall boat and $8.66 \%, 11.35 \%, 9.95 \%$, and $8.66 \%$ for rowers $\mathrm{A}, \mathrm{B}, \mathrm{C}$, and $\mathrm{D}$, respectively, during the $2-\mathrm{km}$ trial and $9.74 \%$ for the overall boat and $8.14 \%, 9.36 \%$, $15.55 \%$, and $9.33 \%$ for the respective individual rowers during the $5-\mathrm{km}$ trial. The $5-\mathrm{km}$ trial was characterized by a strategy that was more "aggressive" in the first $25 \%$ (113.5\% of the average) but resulted in a smaller end spurt in the final $25 \%$ ( $100.9 \%$ of the average). In comparison, during the $2-\mathrm{km}$ trial the overall strategy was more "conservative" in the initial $25 \%$ (108.1\% of the average) but displayed a greater end spurt in the final $25 \%(105.5 \%$ of the average).

$1<<<<<<<<<$ Figure $1>>>>>>>>>>>>>>>>>>>>1$

Individual rower data indicate that each has a different power profile, and not all mimic the overall boat profile. The stroke (rower A) and bow (rower D) seats produced their highest power during the final epoch, whereas rowers in the middle positions produced their highest power outputs in the opening epoch. In addition, each individual demonstrated a high degree of oscillation in stroke-to-stroke power output throughout the trials. During the 2-km trial, the CVs for stroke-to-stroke power were $12.52 \%, 14.48 \%, 15.16 \%$, and $18.77 \%$ for rowers $\mathrm{A}$, $\mathrm{B}, \mathrm{C}$, and $\mathrm{D}$, respectively, and $10.17 \%$ for overall boat power, whereas during the $5-\mathrm{km}$ trial these were $13.67 \%$, $18.55 \%, 18.55 \%$, and $18.08 \%$ for the individual rowers and $12.48 \%$ for the overall boat. Data are provided for the $2-\mathrm{km}$ trial, and the pattern was similar in the $5-\mathrm{km}$ trial (Figure 2).

$1<<<<<<<<<<<<<<$ Figure $2>>>>>>>>>>>>>>>1$

\section{Discussion}

This study indicates that during on-water rowing, overall boat power profiles in 2- and 5-km trials are similar to velocity profiles previously described for individual rowing ergometry ${ }^{3,4}$ and on-water racing. ${ }^{2}$ However, a remarkable finding is the degree of variation among individual rowers. Indeed, during both trials the overall power profile was mimicked by rowers $\mathrm{A}$ and $\mathrm{D}$ but not $\mathrm{B}$ and $\mathrm{C}$. Based on available data, it is not possible to determine how this individual variation influences overall boat performance. It is possible that a common strategy could have negative consequences if all rowers used their energetic resources at similar rates. Alternatively, variation in individual pacing could influence overall boat mechanical efficiency. Of particular interest are the as-yet- unidentified mechanisms allowing the generation of a seemingly coherent pacing strategy for the whole boat that reflects those reported in other sporting events, despite the lack of synchronization in individual rowers' power profiles.

In line with previous findings regarding self-paced exercise, ${ }^{7}$ our participants illustrated a high degree of nonmonotonic variation in power output that differed substantially between individuals (CVs of $12.52-18.77 \%$ in the $2-\mathrm{km}$ and $13.67-18.08 \%$ in the $5-\mathrm{km}$ ). This observation, in combination with the increased power output in the final $10 \%$ displayed by all rowers, acts as further evidence of a control system that regulates performance to maintain physiological homeostasis.

\section{Practical Applications}

This case study demonstrates that although overall boat power profiles during 2- and 5-km trials appear similar to previously reported on-water and ergometer velocity profiles, there is considerable variation among individual rowers. Further research is warranted to determine the efficacy of different individual rower strategies in relation to overall boat performance. This may result in the ability to recommend position-specific pacing strategies that maximize overall boat performance.

\section{References}

1. Foster C, Snyder AC, Thompson NN, Green MA, Foley M, Schrager M. Effect of pacing strategy on cycle time trial performance. Med Sci Sports Exerc. 1993;25(3):383-388. PubMed

2. Muehlbauer T, Schindler T, Widmer A. Pacing pattern and performance during the 2008 Olympic rowing regatta. Eur J Sport Sci. 2010;5:291-296. doi:10.1080/17461390903426659

3. Garland SW. An analysis of the pacing strategy adopted by elite competitors in $2000 \mathrm{~m}$ rowing. Br J Sports Med. 2005;39:39-42. PubMed

4. Kennedy MD, Bell GJ. Development of race profiles for the performance of a simulated $2000-\mathrm{m}$ rowing race. Can J Appl Physiol. 2003;28:536-546. PubMed doi:10.1139/h03-041

5. Wing AM, Woodburn C. The coordination and consistency of rowers in a racing eight. J Sports Sci. 1995;13:187-197. $\quad \underline{\text { PubMed }}$ doi:10.1080/ $\underline{02640419508732227}$

6. Coker J, Hume P, Nolte V. Validity of the PowerLine boat instrumentation system [abstract]. In: Proceedings of the 27th International Conference on Biomechanics in Sports. 2009[AUQ2].

7. Tucker R, Bester A, Lambert EV, Noakes TD, Vaughn CL, St Clair Gibson A. Non-random fluctuations in power output during self-paced exercise. Br J Sports Med. 2006;40:912-917. PubMed doi:10.1136/ bjsm.2006.026435

8. St Clair Gibson A, Noakes TD. Evidence for complex system integration and dynamic neural regulation of skeletal muscle recruitment during exercise in hu- 
mans. Br J Sports Med. 2004;38:797-806. PubMed doi:10.1136/bjsm.2003.009852

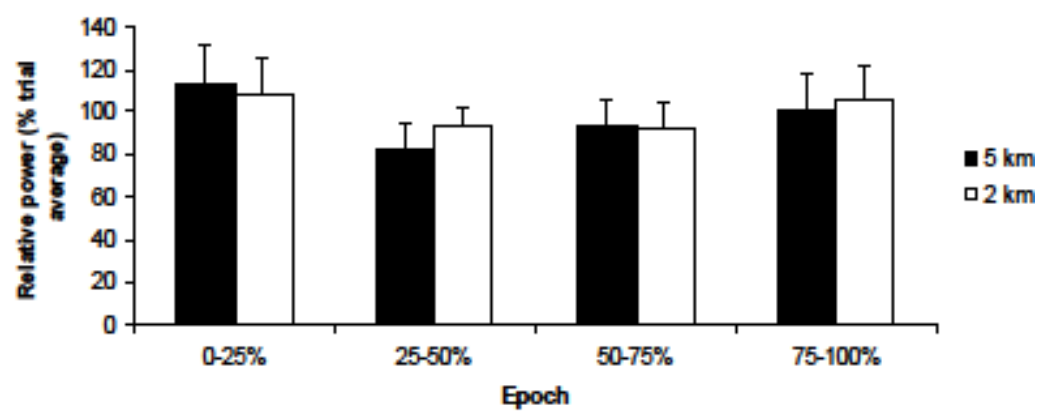

Figure 1 - Overall boat relative power output during the 2- and 5-km trials.
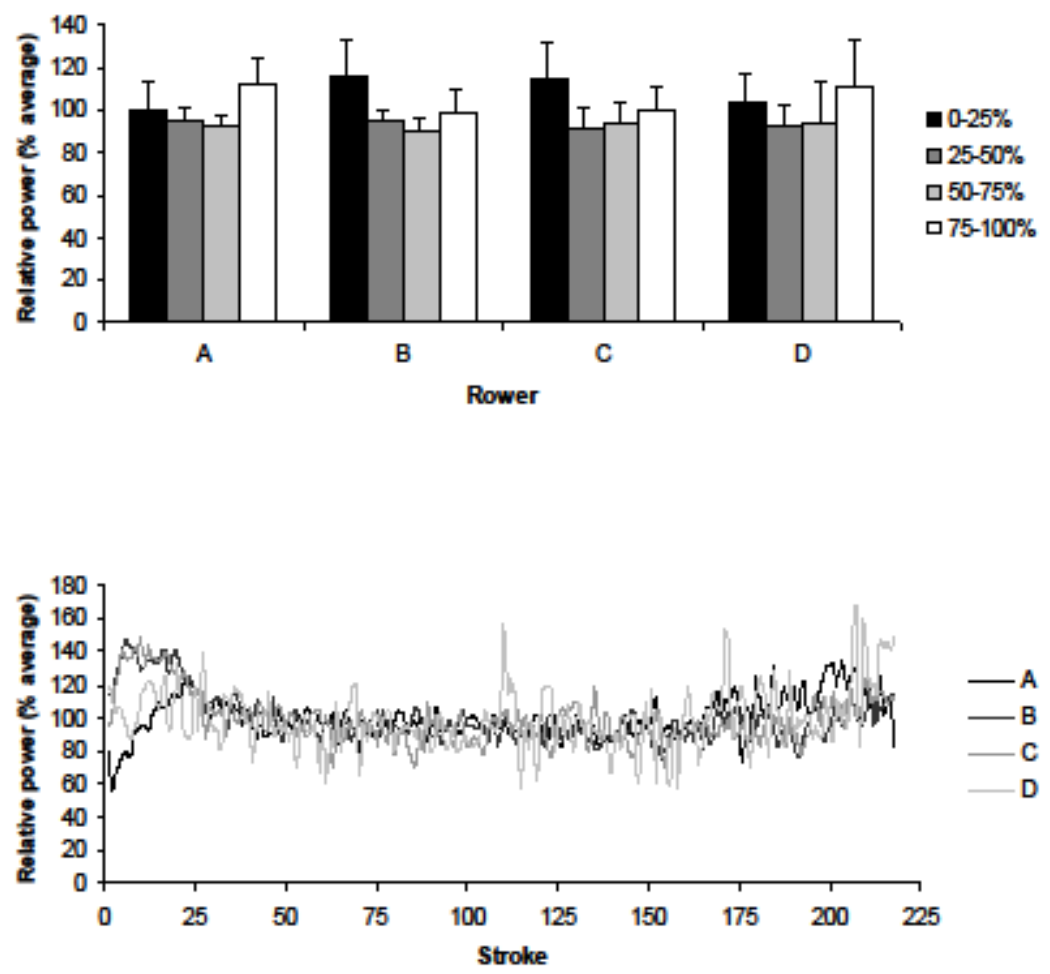

Figure 2 - Relative epoch-to-epoch and stroke-to-stroke power output for individual rowers during the 2-km trial. 


\section{Author Queries}

[AUQ1] Please provide 3 or 4 keywords/phrases for indexing purposes that are not included in the title.

[AUQ2] Who published this, and where? And what is the page number or range for the abstract? 